\title{
ESTUDOS SOBRE A TERCERIZAÇÃO DE SERVIÇOS LOGÍSTICOS REALIZADOS COM FROTA PRÓPRIA: UM ESTUDO DE CASO DA EMPRESA ATACADISTA REDE 100\% MAIS
}

Gabriel Borges Ferreira ${ }^{1}$

FERREIRA, G. B. Estudos sobre a tercerização de serviços logísticos realizados com frota própria: um estudo de caso da empresa atacadista rede $100 \%$ mais. Rev. Ciênc. Empres. UNIPAR, Umuarama, v. 18, n. 1, p. 91-104, jan./jun. 2017.

RESUMO: O setor atacadista tornou-se, com o passar dos anos, um dos grandes expoentes do mercado nacional, porém engana-se quem pensa que as empresas que compõem esse setor têm um dia a dia mais fácil por conta disto. As empresas atacadistas sobrevivem a lutas diárias contra pequenas margens sobre produtos vendidos, concorrência acirrada, muitas vezes desleal, e ao aumento de custos fixos e variáveis. O objetivo deste trabalho é mostrar as vantagens que as empresas podem ter ao substituir serviços logísticos realizados com a frota própria por serviços prestados por uma frota terceirizada. Para alcançar o objetivo proposto, foi utilizado o tipo de pesquisa exploratória, buscando-se embasamento em referenciais teóricos por meio de livros, artigos, revistas e sites. Utilizou-se o tipo descritivo de natureza quantitativa para reunir os dados levantados, junto à empresa objeto de estudo, e dar maior respaldo a pesquisa. A conclusão do estudo foi que, na situação da empresa atacadista analisada, o ideal seria terceirizar os serviços realizados com a frota própria, em busca de vantagens competitivas frente à concorrência.

PALAVRAS-CHAVE: Custos; Frota própria; Logística; Terceirização.

\section{OUTSOURCING OF LOGISTICAL SERVICES CARRIED OUT WITH OWN FLEET: A CASE STUDY OF THE WHOLESALE COMPANY REDE 100\% MAIS}

\begin{abstract}
Over the years, the wholesale sector has become one of the great exponents of the national market, but it is erroneous to think that the companies that make up this sector have an easier routine due to this. Wholesale companies survive daily struggles against small profit margins on products sold, fierce and often unfair competition, and increasing fixed and variable costs. The purpose of this paper is to show the advantages that companies may have when replacing logistics services using their own fleet with services provided by an outsourced company. In order to reach the intended objective, an exploratory approach
\end{abstract}

DOI: $10.25110 /$ receu.v18i1.6198

${ }^{1}$ Administrador especialista pela Universidade Paranaense - UNIPAR, unidade de Umuarama.

E-mail: gabriel_borges26@hotmail.com 
was used, seeking theoretical references in books, papers, journals and websites. A quantitative description was used in order to gather the surveyed data at the studied company, and to provide greater support to the research. This study concluded that, in the situation of the analyzed wholesale company, the ideal would be to outsource the services performed with their own fleet, seeking competitive advantages against the competition.

KEYWORDS: Costs; Logistics; Outsourcing; Own Fleet.

\section{ESTUDIOS SOBRE LA TERCERIZACIÓN DE SERVICIOS LOGÍSTI- COS REALIZADOS CON FROTA PROPIA: UN ESTUDIO DE CASO DE LA EMPRESA ATACADISTA REDE 100\% MAIS}

RESUMEN: El sector mayorista se ha convertido con el paso de los años uno de los grandes exponentes del mercado nacional, pero se equivoca quien piensa que las empresas que componen ese sector tienen un día a día más fácil por cuenta de ello. Las empresas mayoristas sobreviven a luchas diarias contra pequeños márgenes sobre productos vendidos, competencia fuerte, muchas veces desleal, y el aumento de costos fijos y variables. El objetivo de este trabajo es mostrar las ventajas que las empresas pueden tener al reemplazar servicios logísticos realizados con la flota propia por servicios prestados por una flota tercerizada. Para alcanzar el objetivo propuesto se utilizó el tipo de investigación exploratoria, buscando basamento en referenciales teóricos por medio de libros, artículos, revistas y sitios. Y, el tipo descriptivo de naturaleza cuantitativa para reunir los datos levantados, junto a la empresa objeto de estudio, y dar mayor respaldo a la investigación. La conclusión del estudio fue que en la situación de la empresa mayorista analizada lo ideal sería subcontratar los servicios realizados con la flota propia, en búsqueda de ventajas competitivas frente a la competencia.

PALABRAS CLAVE: Costos; Flota propia; Logística; Tercerización.

\section{INTRODUÇÃO}

Cada vez mais as empresas estão dedicando parte do seu tempo para a profissionalização da administração de suas empresas, definindo suas estratégias de negócios com bases em um mercado altamente competitivo e globalizado. Esse fenômeno é ainda mais agudo no Brasil, cujo panorama econômico é instável e demanda um forte controle por parte dos gestores para manter um nível de eficiência aceitável.

$\mathrm{O}$ atacado, pela sua representatividade em números na economia brasileira, aparece como um dos principais setores que demandam uma gestão profissionalizada para sua perpetuação. Grande gerador de riquezas, esse setor deu os primeiros passos no Brasil em meados da década de 50, por meio de portugueses imigrantes que aqui chegaram. A princípio, os portugueses exerciam as suas 
vendas em caixas de madeira (caixeiro-viajante) vendendo de casa em casa, ou em pequenos varejos, posteriormente evoluindo para a modalidade de atacado balcão (estabelecimentos com equipes de vendedores internos e preparados para atender os clientes). As primeiras grandes empresas surgiram nas principais capitais brasileiras que, apesar de atuarem basicamente na forma de balcão, já possuíam vendedores cobrindo o interior do país, realizando negócios e enviando as mercadorias aos seus clientes por meio de transporte ferroviário (MACHADO, 2000 apud TUPY; SOUZA, 2006).

As empresas que formam esse grande setor, são responsáveis pela comercialização e distribuição de produtos alimentícios, bebidas, produtos de higiene pessoal, produtos de limpeza doméstica, produtos farmacêuticos, materiais de construção, além de muitos outros. Dessa forma, para cumprir a sua missão exemplarmente, os atacadistas necessitam manter as operações logísticas de armazenamento, estoques, transportes, embalagem e manuseio de materiais sobre rígida gestão e atenta supervisão, para que os custos e os tempos de processamentos sejam os mínimos possíveis.

De forma abreviada, a logística se traduz no planejamento e gestão do transporte, estoque, instalações e tecnologia da informação relacionada com a movimentação de insumos, matérias primas, produtos, informações e/ou serviços ao longo da cadeia de suprimentos. A gestão logística pode ser crucial para o aumento da produtividade e da eficiência, principalmente, em um contexto de negócios globalizado (FAÇANHA; SILVA; FELDMANN, 2010, p. 3)

A figura a seguir, consegue por meio dos números do setor atacadista mostrar a importância e a representatividade dessas empresas para economia brasileira.

Figura 1: O Segmento Atacadista Distribuidor em 2014

\section{OSEGMENTO ATACADISTADISTRIBUIDOREM 2014 \\ (Crescimento em relação a 2013)}

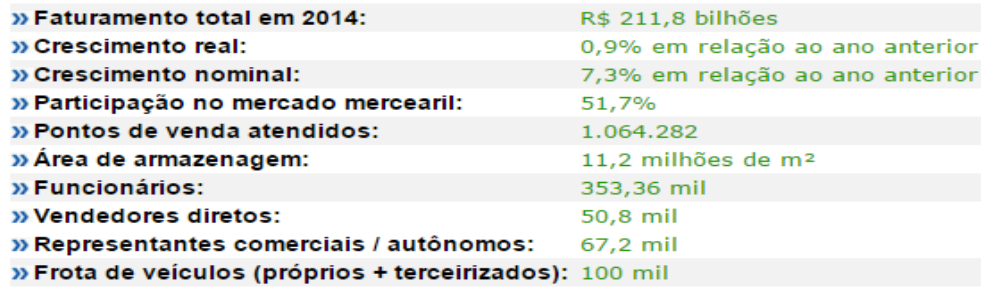

Fonte: Associação Brasileira de Atacadista e Distribuidores de Produtos Industrializados, 2015. 
Segundo a Associação Brasileira de Atacadista e Distribuidores de Produtos Industrializados o estado do Paraná mantém a participação de 4,5\% do valor do faturamento total do ano de 2014, ocupando a $6^{\text {a }}$ lugar entre os estados brasileiros. Os estados de Minas Gerais, São Paulo, Rio de Janeiro, Maranhão, Bahia, ocupam as primeiras posições com os percentuais, $17,1 \%, 14 \%, 10,7 \%$, $5,2 \%, 4,6 \%$, consecutivamente.

Visando a relacionar a gestão profissionalizada, de um participante do setor atacadista brasileiro, com as abordagens de operações logísticas da cadeia de suprimentos, pesquisadas e difundidas por alguns dos autores mais conceituados a níveis mundiais, esse trabalho se encontra estruturado da seguinte maneira: Introdução ao setor atacadista; Local e metodologia de pesquisa; Referencial bibliográfico acerca dos custos logísticos e terceirização; Levantamento de dados e cálculos e a conclusão.

A partir dessa relação, buscou-se verificar a viabilidade da terceirização dos serviços logísticos que, a princípio, são realizados pela frota própria da empresa atacadista Rede 100\% Mais.

\section{REVISÃO BIBLIOGRÁFICA}

\subsection{Logística e Custos no transporte}

As operações comerciais, fonte do desenvolvimento logístico e de cadeias de suprimentos, foram também responsáveis pelos primeiros eventos da história da administração. Em 3.000 a.C., na Mesopotâmia, a civilização suméria escriturou os primeiros registros de operações de comércio.

Caracterizada pela sua prática desde o surgimento dos primeiros agrupamentos humanos, a Administração, segundo Maximiano (2012), é o processo de tomar decisões sobre objetivos e utilizações de recursos. Já as operações logísticas tiveram seus primeiros registros datados no século XVI a.C., no Egito. Onde, a conceitos de logística foram utilizados em ambientes militares para a proteção das suas províncias. Mais tarde, no século XVI d.C., em Veneza, na Itália, a administração de materiais é utilizada novamente por forças militares.

O surgimento de teorias e ideias acerca da administração são bem antigas. Ainda segundo Maximiano (2012), na raiz do uso frequente da palavra Administração, está o processo de resolução dos problemas. A origem dessa ciência é o processo de tomar decisões para resolver problemas, do presente e do futuro, especialmente quando há o envolvimento de organizações.

Como mencionado a logística existe desde o começo da civilização, mas foi a partir século XXI, com a implementação de melhores práticas, que se tornou uma área operacional mais estimulante e desafiadora da gestão da cadeia de suprimentos.

Segundo Bowersox (2014), logística se refere à responsabilidade de projetar e administrar sistemas para controlar o transporte e localização geográ- 
fica dos estoques de matérias-primas, de produtos em processo e acabados, com um esforço integrado para atingir a satisfação do cliente pelo menor custo total. Complementando as ideias comentada, Ballou (2001) observa que o transporte é geralmente o elemento mais importante nos custos logísticos, para a maioria das empresas. A movimentação de fretes absorve entre um e dois terços do total dos custos logísticos. Assim, o profissional de logística necessita de um bom entendimento das questões de transporte.

Ainda de acordo com Bowersox (2014), três fatores são fundamentais para a logística, os custos, a velocidade e consistência. Custos do transporte envolve o pagamento feito para o carregamento entre duas localizações geográficas, além das despesas para manter o estoque em trânsito. O sistema logístico deve utilizar os transportes que minimizem o custo total do sistema. Isso implica que que o meio menos dispendioso de transporte pode não resultar no menor custo total da logística.A velocidade do transporte implica no tempo necessário para completar uma movimentação de um local para outro. Desse modo, a velocidade e o custo do transporte se relacionam de duas formas, primeiro, as empresas de transporte com condições de oferecer serviços mais rápidos, geralmente cobram tarifas mais altas; segundo, quanto mais rápido for serviço de transporte, menor será o tempo em que o estoque fica em trânsito e indisponível. Assim, um aspecto crítico da seleção do método de transporte é o equilíbrio entre o custo do serviço e a velocidade.

A consistência do transporte faz referência às variações no tempo necessárias para realizar determinada movimentação em certo número de carregamentos. A consistência reflete a confiabilidade do transporte. Se transporte entre dois locais leva três dias na primeira vez e seis na segunda, essa variação inesperada pode causar sérios problemas operacionais na cadeia de suprimentos. Quando o transporte não é consistente, é imperativo fazer estoques de segurança para se resguardar contra interrupções no serviço que têm impacto sobre o empenho geral do estoque do comprador e do vendedor (BOWERSOX, 201).

Portanto, depois destas ponderações é possível constatar que e escolha do modal correto para realização do transporte do seu produto é extremamente complexa e dispendiosa. Deve ser feita com muito embasamento para que não haja engano no momento de optar pelo melhor meio.

O modal de transporte rodoviário se expandiu rapidamente desde o fim da Segunda Guerra Mundial. Ballou (2001) aponta que as vantagens inerentes do modal rodoviário são: seus serviços porta a porta de modo que nenhum carregamento ou descarregamento é exigido entre a origem e o destino; sua frequência e disponibilidade de serviços e sua velocidade e conveniência nos serviços porta a porta.

Observa-se também que esse modal apresenta um investimento fixo relativamente baixo, quando comparado com outros modais. Além de operar em estradas financiadas e mantidas com dinheiro público. 
No entanto, esse modal não está livre de problemas deste modo, isso será um fator extremamente considerado. Conforme Bowersox (2014) avaliou em sua obra, em um capítulo reservado para o serviço de transportes, os custos de taxas de licenciamento, pedágios e impostos são consideráveis, porém estão relacionadas ao número de caminhões e de quilômetros que são percorridos.

Além disso, as principais dificuldades são o aumento do custo de reposição de equipamentos, a manutenção, a segurança, a falta de motoristas, a regulamentação de horário de trabalho dos caminhoneiros, os salários dos trabalhadores e o custo de combustíveis. As operações de caminhões são caracterizadas por custos fixos baixos e custos variáveis altos (BOWERSOX, 2014). Alvarenga (2000), afirma que os custos relacionados com a função de transportar são os custos diretos e indiretos. São custos diretos aqueles que se relacionam diretamente com a função produtiva de transportar. São eles (1) Depreciação do veículo; (2) Remuneração do capital; (3) Salário e gratificações de motoristas e ajudantes; (4) Cobertura de risco (seguro); (5) Combustível; (6) Lubrificação; (7) Manutenção; (8) Pneus; (9) Licenciamento e demais impostos.

Porém, existem despesas que não se relacionam diretamente com a operação em si. Alguns exemplos são a contabilidade da empresa, o setor de pessoal, a administração de uma maneira geral. Esses custos são denominados de custos indiretos.

Ainda, segundo Alvarenga (2000), os custos diretos podem ser subdivididos em custos fixos e variáveis. No caso do modal em análise a variável operacional de referência será a distância percorrida pelo veículo. Os custos variáveis são (1) Combustível; (2) Lubrificação; (3) Manutenção; (4) Pneus. Já os custos fixos são os seguintes (1) Depreciação; (2) Remuneração do capital; (3) Salários e gratificações de motoristas e ajudantes; (4) Cobertura de risco (seguro); (5) Licenciamento e demais impostos.

\subsection{Terceirização}

O termo terceirização assusta boa parte dos ouvintes, principalmente, os empregados com carteira assinada. É compreensível o alarde, tendo em vista, que em cada situação em que a terceirização é ponto central as mudanças são grandes.

No entanto, as grandes mudanças não são em sumo apenas ruim. $\mathrm{Na}$ verdade, os benefícios são muito maiores e bem mais generosos com o passar do tempo. A termo terceirização é relacionado com o fornecimento de produtos, bens ou serviços, antes produzidos ou realizados pela própria empresa, à uma outra empresa (BERTAGLIA, 2003, apud SILVA; GANDOLPHO; CARNIELLO, 2012). Ainda conforme os autores, terceirizar é parte importante de muitas estratégias empresariais, afinal ela permite que a empresa centralize os seus esforços em suas atividades principais. Complementando, Baily et al. (2000) a terceirização é a contratação externa de atividades consideradas secundárias. 
Ao analisar uma terceirização, as empresas avaliam vários pontos em relação a suas operações logísticas, como o custo real de cada atividade, a necessidade de controle direto sobre as mesmas e a possibilidade do desenvolvimento de conhecimento interno para futuras melhoras no gerenciamento dessas operações. Dessa maneira, fica evidente a necessidade de avaliar os custos, porém é de extrema importância ponderar o nível de serviço a ser entregue ao cliente (FIGUEIRA, 2001 apud SILVA; GANDOLPHO; CARNIELLO, 2012).

Dessa forma, volta-se ao impasse inicial entre os pontos positivos e negativos da terceirização. As oportunidades de terceirização na logística são grandes, mas são acompanhadas de riscos na mesma proporção. No entanto, esses riscos são mensuráveis e passíveis de análises, sendo o maior risco não realizar as devidos estudos dos riscos e oportunidades da terceirização.

O nível de competição global no âmbito empresarial é elevadíssimo, empresas buscam diariamente inovar em novos produtos, buscar novos potenciais clientes e estruturas maiores e mais produtivas. Muitos recursos financeiros são destinados para estudos para esses fins, mas pouca atenção é dispendida para áreas como a logística, apesar da sua importância para grande máquina empresarial. Dessa maneira, as terceirizações implementadas, de uma maneira cuidadosa e correta, nas operações logísticas podem reduzir custos e criar um vantagem competitiva frente à concorrência.

Segundo Figueira (2001 apud SILVA; GANDOLPHO; CARNIELLO 2012) afirmam que as vantagens da terceirização não são restritas apenas a custos. A melhora na prestação do serviço ao cliente é, visivelmente, perceptível à medida que a empresa consegue firmar parceria com um único operador logístico. Esse acordo seria capaz de tornar a empresa mais flexível às mudanças do mercado, a velocidade como os materiais fluem é aumentada e os níveis de estoques são reduzidos. Mas, a principal vantagem é o fato de a empresa conseguir ter acesso às novas técnicas de gerenciamento logístico que as empresas especializadas desenvolvem, uma vez que a própria empresa não consegue manter em sua estrutura interna devido ao fato de a logística não ser sua atividade principal.

Ballou (2006) aponta os seguintes benefícios oriundos da terceirização: (1) Custos reduzidos e menores investimentos de capital; (2) Acesso às tecnologias novas e a habilidade gerenciais; (3) Vantagens competitivas como a crescente penetração no mercado; (4) Acesso incrementado à informação útil para o planejamento e; (5) Redução dos riscos e incerteza.

$\mathrm{O}$ autor demonstra muita precisão ao abordar benefícios que traduzem totalmente o "por que" terceirizar a logística em algumas ocasiões. Ainda, afirmou que as principais vantagens são a redução de custos e investimentos em áreas que não são as principais da empresa. Porém, surge a necessidade de gerenciamento dos serviços prestados pelo operador logístico, para que não resultem em prejuízos capazes de superar os benefícios acima expostos (BALLOU, 2006). 


\section{METODOLOGIA}

\subsection{Local de pesquisa}

O trabalho foi realizado em parceria com a Rede de Supermercados 100\% Mais, localizada na cidade de Maringá, estado do Paraná. A central atacadista de distribuição da Rede 100\% foi idealizada pelos seus sócios, proprietários de mercados, que buscavam montar parcerias para conseguir melhores preços nas compras de grandes quantidades de produtos estratégicos no ramo varejista de produtos alimentícios.

A empresa possui sede própria com ótima estrutura e localização na cidade canção. Na sede, funciona a administração central do atacado Rede $100 \%$ Mais e a área de distribuição dos produtos. A empresa possui frota própria de maquinários e veículos de transporte de cargas. Veículos esses que serão objetos desse estudo com intuito de tornar as operações de transportes mais rentáveis para a empresa.

\subsection{Métodos utilizados}

Na elaboração deste trabalho o pesquisador utilizou o método de pesquisa exploratória de natureza quantitativa.

De acordo com Gil (1999, p. 43) as pesquisas exploratórias são

[...] desenvolvidas com o objetivo de proporcionar visão geral, de tipo aproximativo, acerca de determinado fato. Este tipo de pesquisa realizado especialmente quando o tema escolhido é pouco explorado e torna-se difícil sobre ele formular hipóteses precisas e operacionalizáveis.

A natureza quantitativa vem mensurar como os dados produziram os resultados dos estudos. Lakatos e Marconi (1991) definem a pesquisa quantitativa em investigações de pesquisa empírica, cuja principal finalidade é o delineamento ou análise das características de fatos ou fenômenos.

Com a opção pelos métodos acima foi possível coletar os dados junto à empresa e aplicar os estudos difundidos por pesquisadores, para alcançar resultados que agreguem melhoras ao sistema até então utilizados pelos gestores.

\subsection{Instrumentos utilizados}

Os resultados deste trabalho foram alcançados a partir da utilização de instrumentos de pesquisas que permitissem buscar dados junto ao local de pesquisa e assim, relacioná-los com estudos que estavam contidos em obras de autoria de grandes pensadores sobre o tema central deste texto.

Dessa maneira, foram utilizados os instrumentos a pesquisa bibliográfica e documental, que forneceram o conhecimento base para aplicação de te- 
orias junto ao estudo de caso. Esse procedimento foi ainda subdivido por Gil (2007) em três partes. Na Pré-análise organizou-se as informações coletadas. Já na segunda parte, a "Exploração material", administra-se as decisões tomadas na Pré-análise. Na terceira e última fase "Tratamento dos dados", por fim ocorreu a interpretação, que objetivou tornar os dados válidos e significativos. Além disso, a análise do conteúdo selecionado junto ao Atacadista determinou os pontos críticos a serem promovidas mudanças.

\section{RESULTADOS E DISCUSSÃO}

\subsection{Métodos de cálculos}

Com base nos custos exemplificados anteriormente foi possível elaborar um planilha, seguindo ainda o modelo desenvolvido por Alvarenga e Novaes (2000) em sua obra. Esses dados foram listados de uma forma que apresentasse no final um custo por quilômetro rodado.

A empresa pesquisada possui quatro veículos utilizados para os serviços logísticos de transporte de produtos a clientes. Para finalidade de calcular o custo total por quilômetro percorridos foi selecionado um único veículo, uma vez que todos os demais veículos são do mesmo modelo e equipados com o mesmo equipamento. Dessa forma, o entendimento do cálculo e a análise do resultado se tornam mais fácil.

Quadro 1: Veículos e Equipamentos da Frota Própria

\begin{tabular}{|l|c|}
\hline \multicolumn{1}{|c|}{ Veículo/Equipamento } & Valor de compra \\
\hline Caminhão truck Atego 2425 2010/2011 & $\mathrm{R} \$ 192.760,00$ \\
\hline Baú Sider Randon & $\mathrm{R} \$ 35.000,00$ \\
\hline Total & $\mathrm{R} \$ 227.760,00$ \\
\hline
\end{tabular}

Fonte: Elaborado pelo autor (2015). 
Quadro 2: Planilha de Custos Fixos e Variáveis Frota Própria

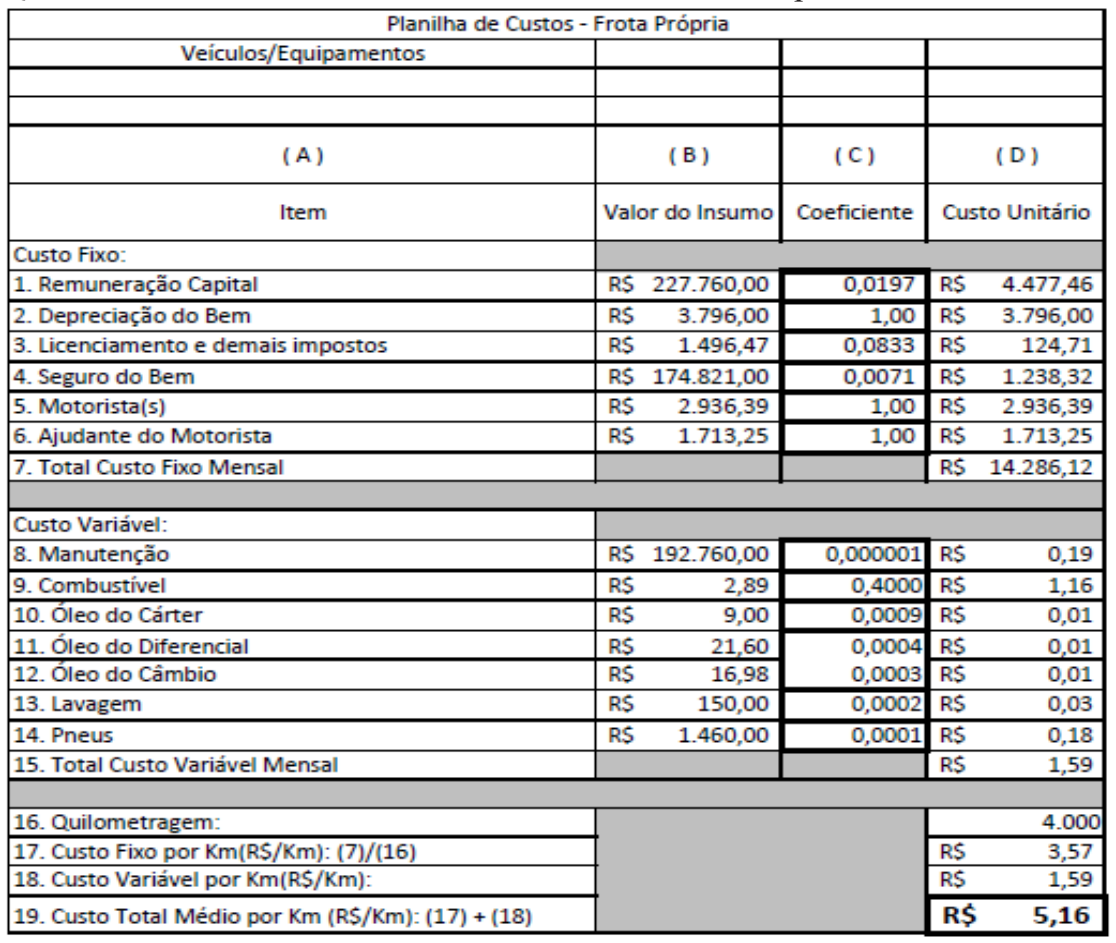

Fonte: Elaborado pelo autor (2015).

O primeiro dado ser listado é o de Custo Capital. Nesse momento, a empresa, mensalmente, separa um valor para que no fim da vida útil do bem tenha o valor disponível para substituí-lo. Para o cálculo foi utilizado os valores de aquisição dos bens novos, conforme planilha abaixo. O valor do Coeficiente multiplicador do Custo Capital é dado pelas próximas expressões:

Figura 2: Fórmulas do Coeficiente Multiplicador do Custo Capital

$$
\begin{gathered}
C=(I-V R) \cdot F R C+V R \cdot j \\
F R C=\frac{\mathrm{j} \cdot(1+j)^{n}}{(1+j)^{n}-1}
\end{gathered}
$$

Fonte: Alvarenga e Novaes (2000, p. 97).

Onde:

I = Investimento para adquirir um veículo novo; 
$\mathrm{VR}=$ Valor residual do veículo;

FRC $=$ Fator de recuperação do capital;

$\mathrm{j}=$ Taxa de juros ou de oportunidade, em porcentagem, divida por cem;

$\mathrm{n}=$ vida útil veículo;

A taxa de Juros ou Oportunidade utilizada na fórmula foi a média da Taxa do CDI, uma vez que essa taxa é o principal indicador para os investimentos realizado no país. A fonte utilizada foi o jornal Valor Econômico, referência no mercado brasileiro.

Dessa forma, o próximo custo é a Depreciação mensal do bem e o Licenciamento e os Demais Impostos. O Coeficiente utilizado na linha três foi alcançado devido a divisão do valor anual em meses, ou seja, 1/12.

O quarto item dos custos fixos é o seguro do bem, a condição do seguro é muito peculiar, influenciado diretamente pela situação atual do bem segurado, os estados a serem percorridos pelo caminhão e também pelo nível de sinistros computados pelo mercado segurador. Alvarenga e Novaes (2000) mencionam em sua obra que o valor médio estimado para o valor do seguro de um veículo de transporte é de $6 \%$ a $8 \%$ do seu valor. Dessa maneira, foi realizado um levantamento junto às seguradoras que atendem esse ramo de atividade e foi comprovada esta informação. As cotações mantiveram o índice de 6,5\% a 8,5\% do valor do bem.

Os últimos custos fixos são os salários do Motorista e o Ajudante do Motorista. Esse valor foi mensurado conforme as planilhas abaixo, por meio dos valores médios, informados da pela empresa, de Salários e Hora Extras. No custo de manutenção, como os registros contábeis estavam de difícil acesso, foi mensurado a partir de instruções do próprio Alvarenga em sua obra. Foi adotado um coeficiente mensal de $10^{-6}$ do valor do veículo novo adotando também a quilometragem mensal média de $4.000 \mathrm{~km}$. Este cálculo refere-se a despesas com manutenção, incluindo despesas com mão de obra e peças de reposição.

O custo variável do Combustível teve seu preço médio, levantado junto a Agência Nacional do Petróleo, Gás Natural e Combustível que realizou uma pesquisa em 10 postos da cidade de Maringá, levantando o preço máximo ao consumidor do Diesel Comum em R\$ 2,89. O Coeficiente multiplicador desta linha foi encontrado por meio da média de consumo do veículo, calculada em 2,5 $\mathrm{km}$ a cada 1 litro de combustível.

Nos itens das linhas dez a doze, os preços foram descobertos a partir de um levantamento junto à concessionária Mercedes Benz, uma vez que adquirido novo o veículo a montadora exige que as revisões sejam realizadas em concessionárias autorizadas para fins de garantia do veículo.

Na pesquisa feita junto a revenda foi relatado que as revisões são realizadas a cada $30.000 \mathrm{~km}$, e essencialmente, são trocados Óleo do Cárter, Óleo do Diferencial e Óleo do Câmbio, na seguinte quantidade 28 litros, 11 litros e 9 li- 
tros, consequentemente, os preços informados na tabela são referentes a um litro.

No item Lavagem foi constado que o valor atual para lavagem de um caminhão do modelo avaliado é de $\mathrm{R} \$ 150,00$. Esse valor é rateado pela quantidade de quilômetros percorridos por mês, assim o veículo manteria uma boa impressão quanto a sua imagem.

Para finalizar o levantamento dos custos variáveis, o último item é o pneu. Porém, se engana que o mesmo não seja importante para a composição do custo. $\mathrm{O}$ custo por unidade de pneu também foi realizado junto a concessionária, esse veículo possui 10 pneus com a medida 275/80/R22,5, no valor de R $\$$ $1.460,00$. O tempo de vida útil médio de um pneu é influenciado pelo volume da carga carregada, a condição da estrada pelas quais o mesmo percorre, pela temperatura e pelos cuidados do proprietário. Dessa maneira, foi estimando um tempo de vida médio de $80.000 \mathrm{~km}$.

\subsection{Considerações finais}

A empresa objeto de estudo possui frota própria responsável pelo transporte dos produtos comercializados a clientes. O veículo selecionado para o levantamento do estudo roda em média $4.000 \mathrm{~km} / \mathrm{mês}$. Esse bem gera um custo fixo de $\mathrm{R} \$ 3,57 /$ por $\mathrm{km}$ e um custo variável de $\mathrm{R} \$ 1,59 /$ por $\mathrm{km}$, somando um custo total de $\mathrm{R} \$ 5,16$ por quilômetro percorrido, conforme resultado da planilha dois.

Em um levantamento feito na cidade de Maringá e região, foi possível notar que existem operadores logísticos que conseguiriam atendê-la com valores inferiores aos custos acima.

Ao optar por um único operador logístico, os valores praticados pelas empresas são de R \$ 4,80 por quilômetro percorrido. São empresas que apresentam Know-how em operações logísticas, o negócio principal dessas empresas são soluções em transportes, por isso consegue apresentar um valor acessível e tecnologias adequadas para o setor.

No entanto, durante o levantamento destes dados foi possível encontrar outra oportunidade que também mostrasse muito atraente. As empresas agenciadoras de cargas surgem como uma opção atraente já que oferecem um serviço que busca atender as exigências do cliente a um preço de $\mathrm{R} \$ 3,75$ por quilômetro percorrido.

Dessa maneira, nota-se que a empresa pesquisada não consegue utilizar o transporte com frota própria como uma vantagem competitiva. O custo total por quilômetro percorrido está acima do valor praticado pelas outras opções do mercado. Assim, a opção de substituir a frota própria por uma frota terceirizada passa a ser considerada como uma forma de realizar menos investimento em veículos e assim destinar esses valores em atividades principais da empresa.

Em último caso, a empresa pode considerar a ideia de reestruturar a frota própria, podendo, vender determinada quantidade de veículos e mesclar 
os serviços de transporte, entre frota própria e frota terceirizada. Isso faria com que a empresa reduzisse custos, tornando-se mais eficiente e rentável, mantendo disponibilidade de veículos para entregas emergenciais.

\section{REFERÊNCIAS}

ALVARENGA, A. C.; NOVAES, A. G. N. Logística aplicada: suprimento e distribuição física. 3. ed. São Paulo. Edgard Blucher, 2000.

BALLOU, R. Gerenciamento da cadeia de suprimentos: logística empresarial. 5. ed. Porto Alegre: Bookman, 2006.

Gerenciamento da cadeia de suprimentos: planejamento, organização e logística empresarial. 4. ed. Porto Alegre: Bookman, 2001.

BOWERSOX, D. J. Gestão logística da cadeia de suprimentos. 4. ed. Porto Alegre: AMGH, 2014.

BERTAGLIA, P. R. Logística e gerenciamento na cadeia de abastecimento. São Paulo. Saraiva, 2003.

BAILY, P. et al. Compras: princípios e administração. São Paulo. Atlas, 2000.

FIGUEIRA, T. Quando e como sua empresa deve decidir pela terceirização das operações logísticas. Jan, 2001. Disponível em:<http://www.guialog.com. br/ ARTIGO148.htm> Acesso em: 23 mai. 2006.

SILVA, J. L.; GANDOLPHO, M. R.; CARNIELLO, M. F. Comparação dos custos entre frota própria e terceirizada em uma transportadora do Vale do Paraíba - SP. Agosto, 2012. Revista de Ciências Gerenciais. Anhanguera Educacional Ltda., 2012.

TUPY, O.; SOUZA, A. P. Eficiência produtiva do setor atacadista/ distribuidor no Brasil. Julho, 2006. Disponível em: $<$ https://www.embrapa. br/pecuaria-sudeste/busca-de-publicacoes/-/publicacao/47500/eficienciaprodutiva-do-setor-atacadista--distribuidor-no-brasil>, Acesso em: 01 set. 2015.

FAÇANHA, S. L. de O.; SILVA, M. A.; FELDMANN, P. R. Tendências e desafios brasileiros na logística globalizada do século XXI. Setembro, 2010. Disponível em: < http://www.ead.fea.usp.br/semead/13semead/resultado/ trabalhosPDF/293.pdf>, Acesso em: 01 set. 2015. 
GIL. Como elaborar projetos de pesquisa. 3. ed. São Paulo. Atlas, 1991.

\section{LAKATOS, E. M.; MARCONI, M. A. Fundamentos da metodologia}

cientifica. 3. ed. São Paulo. Atlas, 1991.

MAXIMIANO, A. C. A. Teoria geral da administração: da revolução urbana à revolução digital. 7. ed. São Paulo. Atlas, 2012.

ANP, Agência Nacional do Petróleo, Gás Natural e Biocombustíveis. Setembro, 2015. Disponível em: $<$ http://www.anp.gov.br/preco/prc/Resumo_Por_ Municipio_Posto.asp>, Acesso em: 20 set. 2015.

NÚMEROS do Setor. ABAD, Associação Brasileira de Atacadistas e Distribuidores de Produtos Industrializados. Setembro, 2015. Disponível em:<http://www.abad.com.br/ds_numeros_setor.php>, Acesso em: 20 set. 2015. 